\title{
ChemComm
}

Check for updates

Cite this: Chem. Commun., 2020, 56, 3592

Received 25th January 2020, Accepted 26th February 2020

DOI: 10.1039/d0cc00681e

rsc.li/chemcomm

\section{Carbon and carbon composites obtained using deep eutectic solvents and aqueous dilutions thereof}

\author{
Gaspar Carrasco-Huertas, (D) Rafael J. Jiménez-Riobóo, María Concepción Gutiérrez, (D) * \\ María Luisa Ferrer (D)* and Francisco del Monte (D)
}

\begin{abstract}
The aim of this featured article is to illustrate some of the most recent applications of deep eutectic solvents (DESs) in the synthesis of carbon and carbon composites. DESs can be obtained by the complexation of quaternary ammonium salts with hydrogen-bond donors. DESs have typically been referred to as a related class of ionic liquids because they share many properties. However, DESs present the advantage of easier and low-cost preparation. Moreover, their compositional flexibility can eventually be translated into materials that provide advanced functionalities and/or tailored hierarchical structures. Interestingly, the use of the liquid binary mixtures of DESs and $\mathrm{H}_{2} \mathrm{O}$ for the preparation of carbon materials plays a critical role with regard to the achievement of some particular porous morphologies. Herein, we will also summarize some recent studies performed on $\mathrm{DES} / \mathrm{H}_{2} \mathrm{O}$ liquid binary mixtures, revealing the possibility of obtaining new eutectic mixtures upon the simple addition of water to DESs while keeping the DES contents at a certain pseudo-concentrated range. This finding will pave the way to novel applications, especially in those fields in which the preparation of high-tech products via low-cost processes is critical. We hope that this featured article will encourage scientists to explore the promising perspectives offered by DESs and aqueous dilutions thereof.
\end{abstract}

Solvents are of paramount importance in a number of processes like, for instance, the synthesis of drugs or natural compounds, the pollutant extraction from contaminated soils or water, and the absorption of gases. ${ }^{1}$ The homogenization of reagents and products within reaction media is obviously one of the main roles played by solvents. Nonetheless, they can also influence the activation energies and reaction thermodynamics.

Deep eutectic solvents (DESs) have recently emerged as interesting media, where different processes can be carried out as an alternative to regular solvents, e.g., aqueous, non-aqueous, or mixed solvents. As in any eutectic mixture, the melting point of a DES is significantly lower than that of an ideal mixture of its components. DESs are obtained by the complexation of quaternary ammonium salts (as hydrogen bond aceptors, HBAs) with hydrogen bond donors (HBDs). ${ }^{2}$ The most often cited rationalization for this phenomenon is that the charge delocalization occurring through hydrogen bonding between halide anions with hydrogen-donor moieties is responsible for the decrease in the freezing point of the mixture relative

Instituto de Ciencia de Materiales de Madrid (ICMM), Consejo Superior de Investigaciones Científicas (CSIC), Cantoblanco 28049, Madrid, Spain. E-mail: mcgutierrez@icmm.csic.es, mferrer@icmm.csic.es; Fax: +34 913720623; Tel: +34913349000 to the melting points of the individual components. ${ }^{3}$ This view has been recently disputed by Zahn and colleagues ${ }^{4}$ who using $a b$ initio molecular dynamic simulations showed how (1) the charge spreads from the anion to the choline cation and (2) the charge transfer from the chloride anion to the urea molecule is negligible. Actually, more recent $a b$ initio molecular dynamic simulations ${ }^{5}$ and neutron diffraction studies ${ }^{6}$ have revealed the occurrence of many possible hydrogen bond interactions of different strengths among DES constituents, forming an extended hydrogen bond network ${ }^{7}$ similar to those found in crystalline structures. Actually, inelastic neutron scattering studies have indicated that eutectic behaviour emerges when the components mix via hydrogen bonds, the strength of which is weak enough to prevent them from settling into a co-crystal. ${ }^{8}$

DESs share many characteristics of conventional ionic liquids (ILs) - e.g., non-reactive with water and non-volatile while offering certain advantages. For instance, the preparation of eutectic mixtures in a pure state can be accomplished more easily than that of ILs with no need of post-synthetic purification because the purity of the resulting DES will simply depend on the purity of its individual components. Moreover, the low cost of those eutectic mixtures based on readily available components e.g., urea and choline chloride $(\mathrm{ChCl})$ are well-known examples 
but there are many more ${ }^{9}$ - makes them particularly desirable for large-scale synthetic applications, more so than conventional ILs.

These are the reasons why the use of DESs in many diverse applications has grown exponentially over the last few years, following the track initially open by ILs and, more recently, (we could say) surpassing them in some particular fields, mainly in the ones (not a few) where the cost is critical. However, a close inspection of all this recent activity reveals that the use of DESs as solvents in material synthesis can still be considered as sporadic. The preparation of zeolites, ${ }^{10}$ the synthesis of nanoparticles, ${ }^{11,12}$ and certain polymers ${ }^{13}$ are some of the few cases where DESs have been used.

Among all these kinds of materials, polymers are particularly interesting within the context of this review as DES-based carbons can be obtained by polycondensation and subsequent carbonization of the resulting polymer rather than by direct carbonization; ${ }^{14}$ this is the typical process followed for the achievement of IL-based carbons. ${ }^{15}$ It is also worth noting that, in these polycondensations, DESs not only play the typical role of a solvent - e.g., providing a reaction media of a certain viscosity and with negligible vapour pressure - but also contain some molecular precursors and even the structure directing agent (SDA). In other words, DESs behave as the so-called "active DESs" in the work by Alonso and coworkers, ${ }^{16}$ thus allowing the control of the morphology more so than by direct carbonization $^{14}$ - and/or of the chemical composition of the resulting polymer. Based on this and before entering the specific topic of this work, we would like to mention some other examples of polymerizations using "active DESs".

For instance, DESs have been used for the preparation of polyacrylates by free radical frontal polymerization (FP). ${ }^{17}$ Thus, as compared to FPs carried out with regular organic solvents, ionic liquids, or even in a solvent-less fashion, ${ }^{18-23}$ DESs based on mixtures of acrylic monomers such as acrylic or methacrylic acids with $\mathrm{ChCl}$ allow the tailoring of viscosity of the reaction media using mixtures with different molar ratios between the components. ${ }^{24}$ This viscosity control helps in minimizing convection instabilities that can eventually result in front collapse while obtaining high polymer conversions. In addition, DESs offer greater versatility than regular ILs in compositional terms so that a better compromise between viscosity and density of double bonds in the monomer molecule can be achieved. Thus, the simple use of low molecular weight counter ions such as Ch allows to increase the density of double bonds as compared to that in DESs prepared from other alkylammonium salts - e.g., tetrabutyl or tetraethylammonium salts - with higher molecular weight. Finally, it is also worth noting the sustainable character of this synthetic process that is given not only by the high conversions but also by the low cost of the precursors and the possibility of recovering (and hence, recycling) the nonpolymerizable ones - e.g., ChCl. In this featured article, we will not further elaborate on this topic as it has been summarized in detail previously. ${ }^{25}$

Poly(diol-co-citrates) (PDCs) are the second class of polymers prepared with the aid of DESs. ${ }^{26}$ PDCs are biodegradable and biocompatible polyesters ${ }^{27}$ that are used as tissue-engineering scaffolds, gene-delivery and bioimaging systems and, more recently, shape-memory polymers for temperature-controlled drug delivery. ${ }^{28}$ Extending the applications of PDCs to the field of drug delivery is indeed quite interesting. The use of ILs offers an alternative to conventional polycondensations as they combine the capability to work as solvents in polycondensation processes ${ }^{29}$ and as vehicles to deliver active pharmaceutical ingredients (APIs) in the form of ionic liquid salts. ${ }^{30-32}$ Unfortunately, neither the conventional synthetic routes used for the preparation of PDC elastomers nor the IL-assisted ones were suitable for the incorporation of labile APIs as their integrity was typically compromised at the temperatures above $150{ }^{\circ} \mathrm{C}$ used in both processes. Thus, our group looked at DESs composed of one of the precursors and the API. It is worth noting that DES-based APIs are particularly interesting because, as compared to IL-based APIs, they can be prepared from commercial compounds of known purity and toxicity. ${ }^{33,34}$ This approach was explored with the preparation of eutectic and/or near-eutectic mixtures composed of 1,8-octanediol and lidocaine with a melting point of $c a$. $40{ }^{\circ} \mathrm{C}^{26 a}$ This liquid mixture played multiple roles as it contained one of the polymer precursors and the API, and also provided the medium to solubilize the second polymer precursor citric acid, thus helping the polycondensation with 1,8-octanediol to proceed at the temperature of $90{ }^{\circ} \mathrm{C}$ (and even below, if one assumes the long reaction time as the penalty for the low input of energy); this is well below those typically used in this sort of polymerizations. The resulting PDCs behaved as drug-eluting materials with high loadings of lidocaine - because of the stoichiometric ratio in which with the polymer precursor was mixed - entrapped within the polyester network, the controlled release of which was simply based on the biodegradable character of the polymer. This synthetic approach was further extended to compounds that are also capable of forming eutectic mixtures and with different functionalities such as quaternary ammonium and phosphonium salts with antibacterial activity. ${ }^{26 b}$ This topic has also been summarized in detail in previous reviews so readers interested in further details are addressed to those publications. ${ }^{25}$

Thus, this feature article will focus on recent progress in the preparation of different carbon materials and carbon composites e.g., with either multiwall carbon nanotubes (MWCNTs) or graphene oxide (GO) - with hierarchical porous structures after carbonization of the respective resins. Moreover, we will also analyse some physical chemistry studies performed on DES/ $\mathrm{H}_{2} \mathrm{O}$ liquid binary mixtures used for the preparation of resorcinolformaldehyde (RF) resins, which play a critical role in the achievement of the porous structure.

\section{Resins of furfuryl alcohol by polycondensation (for their subsequent carbonization)}

In this case, the DES was composed of $p$-toluenesulfonic acid ( $p$ - $\mathrm{TsOH})$ and $\mathrm{ChCl}$, and acted as a protic catalyst that is typically required for furfuryl alcohol (FA) polycondensation. ${ }^{35}$ After polycondensation and carbonization, the resulting carbon 
exhibited a bicontinuous porous network built of colloidal clusters (Fig. 1). Mimicking this approach, one could also use the same eutectic mixture to catalyze the polycondensation of 2-hydroxymethylthiophene (HMT), either with itself or co-condensed

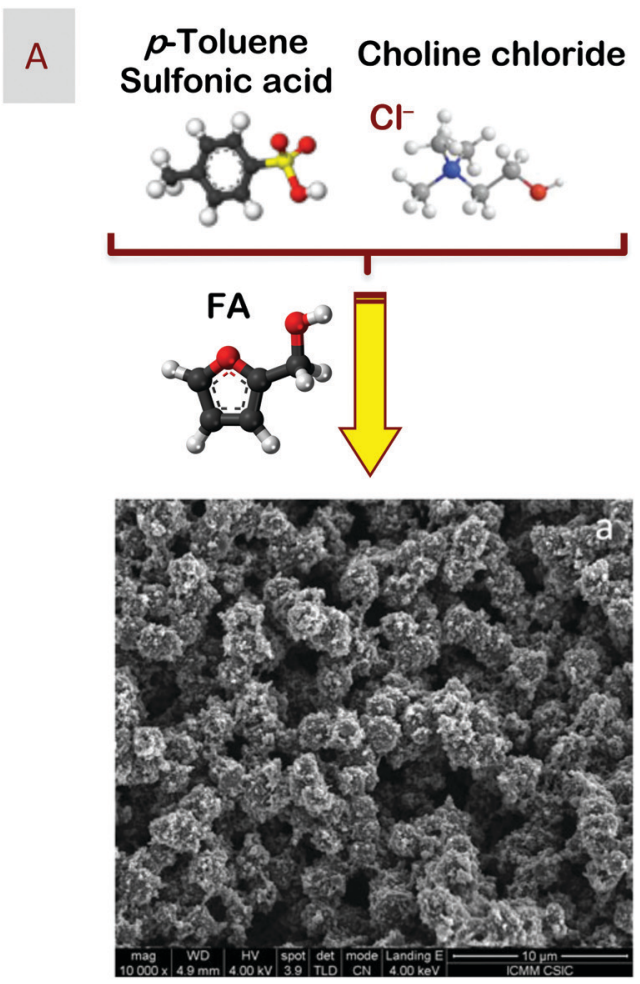

C p-Toluene Choline chloride Sulfonic acid
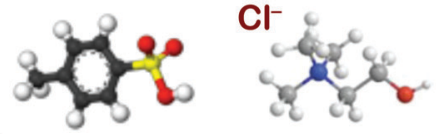

LA
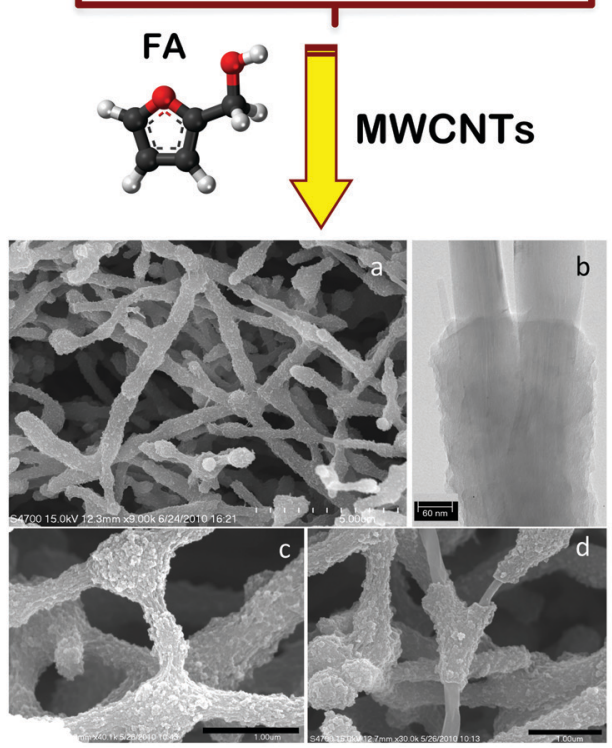

B

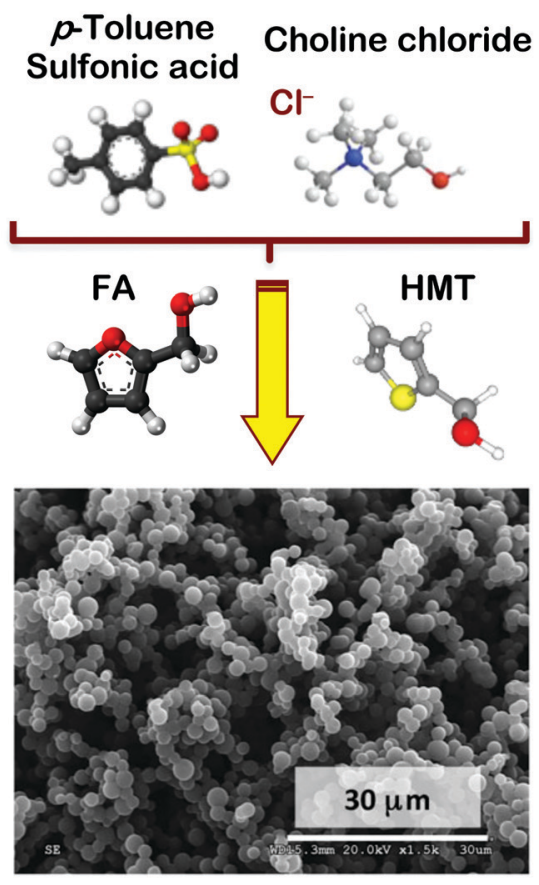

D

\section{Ethylamine Glycerol Phosphoric
hydrochloride}
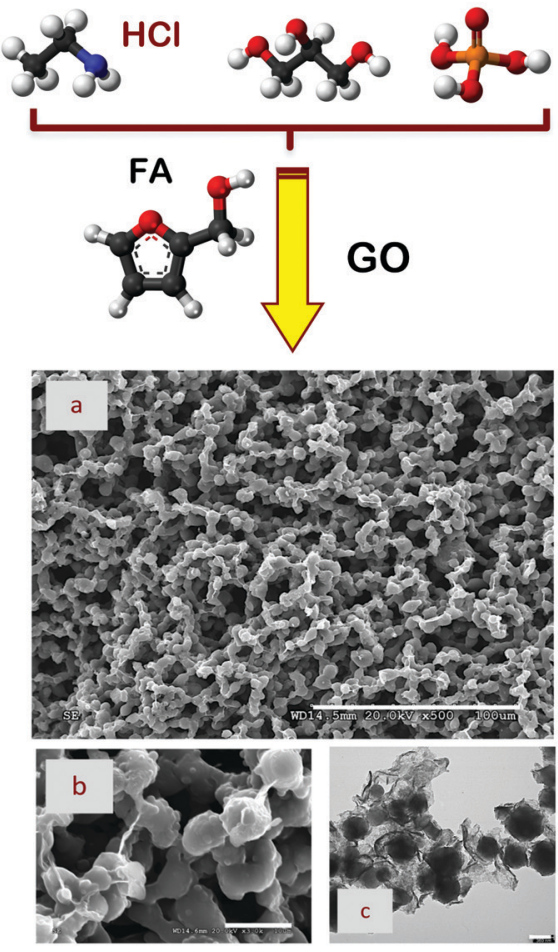

Fig. 1 Scheme representing the catalytic condensation of furfuryl alcohol (FA) and 2-hydroxymethylthiophene (HMT) by the eutectic mixtures of $p$-toluenesulfonic acid and $\mathrm{ChCl}$ for the formation, after carbonization, of (A) carbons, (B) S-doped carbons, (C) carbon-carbon nanotube composites, and (D) carbon-GO composites. SEM micrographs in A, B, C, and D, and TEM micrographs in C and D show the hierarchical structure of the resulting monoliths. Adapted with permission from ref. 35, 36 and 38 . 
with FA, to obtain S-doped carbons. ${ }^{36}$ Depending on the carbonization temperature, S-doped carbons exhibited surface areas ranging from 400 to $775 \mathrm{~m}^{2} \mathrm{~g}^{-1}$ and sulfur contents ranging from 15 to $5 \mathrm{wt} \%$. These features made these materials highly suitable as catalysts for oxygen reduction reactions taking place at the cathode of fuel cells. In particular, S-doped carbons prepared at $900{ }^{\circ} \mathrm{C}$ were particularly efficient for this purpose, with the four-electron-transfer reaction prevailing over the two-electron-transfer one, an excellent resistance to catalyst poisoning in the presence of methanol, i.e., less than $5 \%$ current decrease immediately after methanol addition, and a remarkable stability with a current decrease below $8 \%$ after $20000 \mathrm{~s}$.

It is worth noting that the DES composed of $p$-TsOH and ChCl exhibited a low viscosity - well below those of any of the below-described resorcinol-based DES - so that it was an excellent solvent for the suspension of, for instance, multiwall carbon nanotubes (MWCNTs) or graphene oxide (GO) flakes. ${ }^{35,37,38}$ The incorporation of MWCNTs resulted in significant changes in the morphology of the carbons (Fig. 1). In this case, FA polycondensation occurred on the external surface of MWCNTs so that, after carbonization, carbon coated every MWCNT, forming strong junctions between them. This was actually reflected in both the conductivity - up to $4.8 \mathrm{~S} \mathrm{~cm}^{-1}$, as measured by the four-probe method - and the elastic character Young modulus, $11 \mathrm{MPa}$ - of the resulting monoliths. The combination of high conductivity and high surface area made these composites especially suitable as monolithic electrodes for supercapacitors. Moreover, the elastic features exhibited by these monoliths allowed excellent contact with the current collector that was critical to retain $75 \%$ of the initial capacitance at high current densities up to $29 \mathrm{~A} \mathrm{~g}^{-1}$. Unfortunately, the poor contribution of MWCNTs to the overall capacitance resulted in just a modest capability of energy storage, with specific capacitances not surpassing $120 \mathrm{~F} \mathrm{~g}^{-1} \cdot{ }^{29}$ This performance was surpassed by introducing some phosphorus functionalization that, in addition to the hierarchical structure and good electrical conductivity exhibited by these composites, provided remarkable metrics when they were used as electrodes, in terms of both energy densities (about $22.6 \mathrm{~W} \mathrm{~h} \mathrm{~kg}^{-1}$ ) and power densities (up to $10 \mathrm{~kW} \mathrm{k} \mathrm{g}^{-1}$ ) for operational voltages up to $1.5 \mathrm{~V}^{37}$

In the case of GO-based carbon composites, the morphology of the resulting carbon composites was colloid-like, with flakes entrapped within the colloids (Fig. 1). ${ }^{38}$ Interestingly, carbon composites exhibited certain hydrophilic features (opposite to the typical hydrophobic ones exhibited by bare carbons). In particular, GO-based carbon composite obtained after carbonization at $800{ }^{\circ} \mathrm{C}$ was particularly effective in the range of low partial pressures for the preferential adsorption of water, with water uptakes more than 25 times greater than those of both methanol and ethanol. The combination of high-water uptakes and preferential adsorption of water versus methanol and ethanol found in our carbon-GO composites may make the application of these materials particularly interesting in the processes of bioethanol dehydration.

\section{Resins of resorcinol-formaldehyde by polycondensation (for their subsequent carbonization)}

The carbonization of resins obtained by RF polycondensation is one of the most common synthetic processes used for carbon preparation. ${ }^{39-41}$ The polycondensation reaction is typically carried out in aqueous media and in the presence of either acid or basic catalysts and also on soft or hard templates to finally obtain porous carbon materials. Introducing some textural properties in the resulting carbons is by no means trivial as it ultimately determines the field of application of these carbons, e.g., from water and air purification, adsorption, or catalysis, to electrodes and energy storage. ${ }^{42}$ Unfortunately, the use of hard templates is quite time-consuming with the subsequent cost implications. Moreover, both hard and soft templates are typically difficult to recover, thus further impacting the cost of the process.

The preparation of resorcinol-based DESs has opened interesting perspectives in this field. For instance, Carriazo et al. reported the use of DESs composed of resorcinol and $\mathrm{ChCl}$, or urea, resorcinol, and $\mathrm{ChCl}$ (Fig. 2A) for - upon polycondensation with formaldehyde, i.e., added as an aqueous solution thereof, and subsequent carbonization of the resulting RF resin preparing monolithic carbons with a bimodal porosity within the range of micropores to large mesopores of sizes $c a .10$ and $23 \mathrm{~nm} .{ }^{43}$ The resulting carbons exhibited a bicontinuous porous network built of highly cross-linked clusters that aggregated and assembled into a stiff, interconnected structure. Carbons obtained via spinodal decomposition (SD) processes have typically exhibited this sort of bicontinuous morphology as a consequence of the formation, during polycondensation, of a rich-polymer phase that gets segregated from the non-condensed matter. Along with the advancement in polycondensation, this poorpolymer phase ultimately becomes a depleted-polymer phase, the elimination of which either before carbonization by washing or during carbonization by thermal decomposition finally results in the formation of the above-mentioned bicontinuous porous structure. In our case, we first hypothesized that one of the components forming the DES (e.g., resorcinol) acts as precursor of the polymer phase while the second one (e.g., $\mathrm{ChCl})$ is segregated into the polymer-depleted phase (Fig. 3A and B). More recently, we have studied the aqueous dilutions of DES resulting after the addition of formaldehyde to obtain further insights about whether the mechanism followed in DES-assisted polycondensation is a regular SD process starting in a liquid phase fully homogeneous at both the macro and the nanoscale or not (Fig. 3A, B and D). For those readers interested in this issue, a full description of these studies is provided in the following section of this feature article.

The wide range of DESs that can be prepared provides a remarkable versatility - in both textural and compositional terms to the carbons that can be obtained through this synthetic approach. In textural terms, both the dimensions of the mesopores and the surface area coming from the micropores could be controlled using ternary DESs composed of resorcinol, urea, and $\mathrm{ChCl}$, with different molar ratios of urea. We hypothesized that urea was partially incorporated into the RF network 

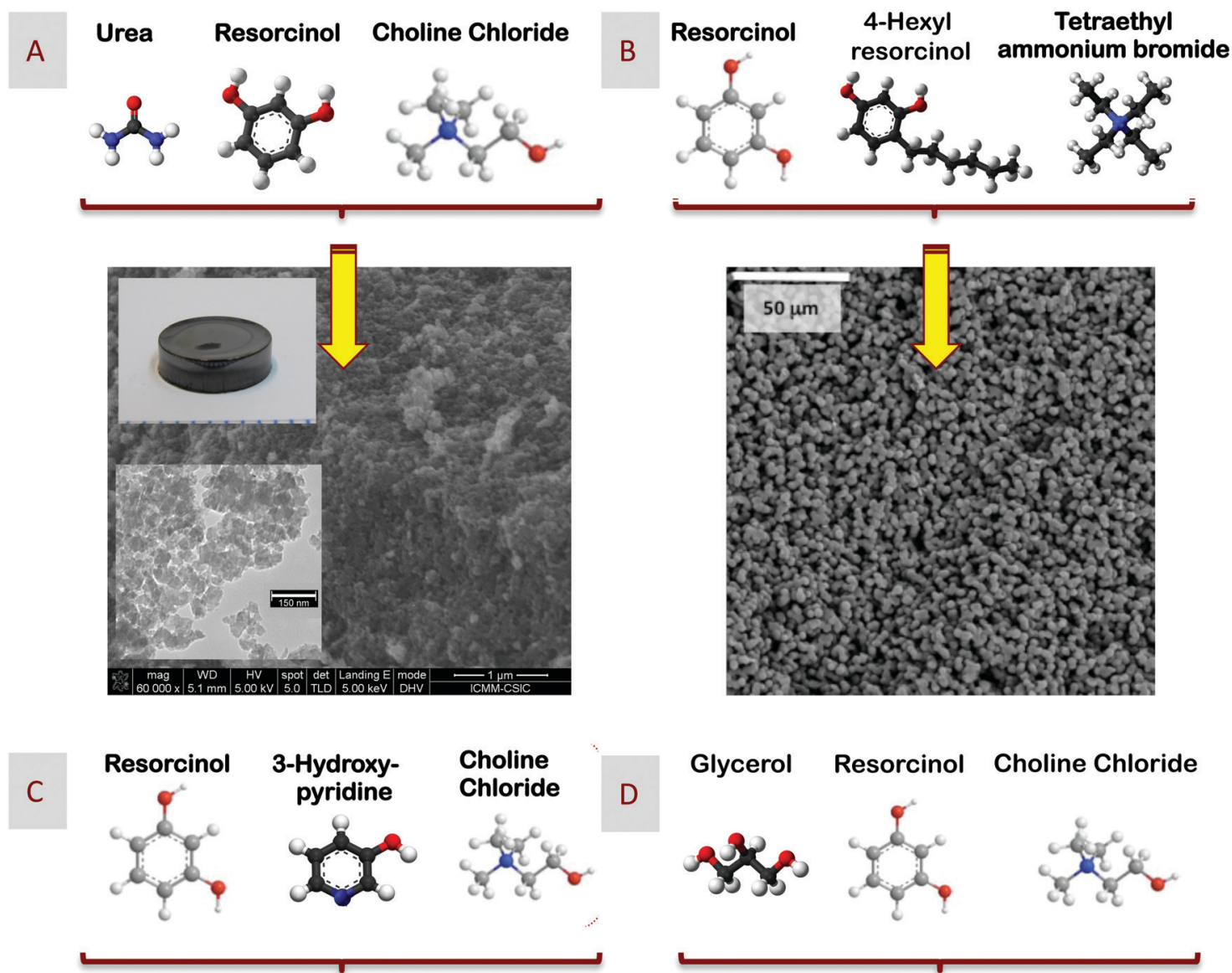

Glycerol Resorcinol Choline Chloride
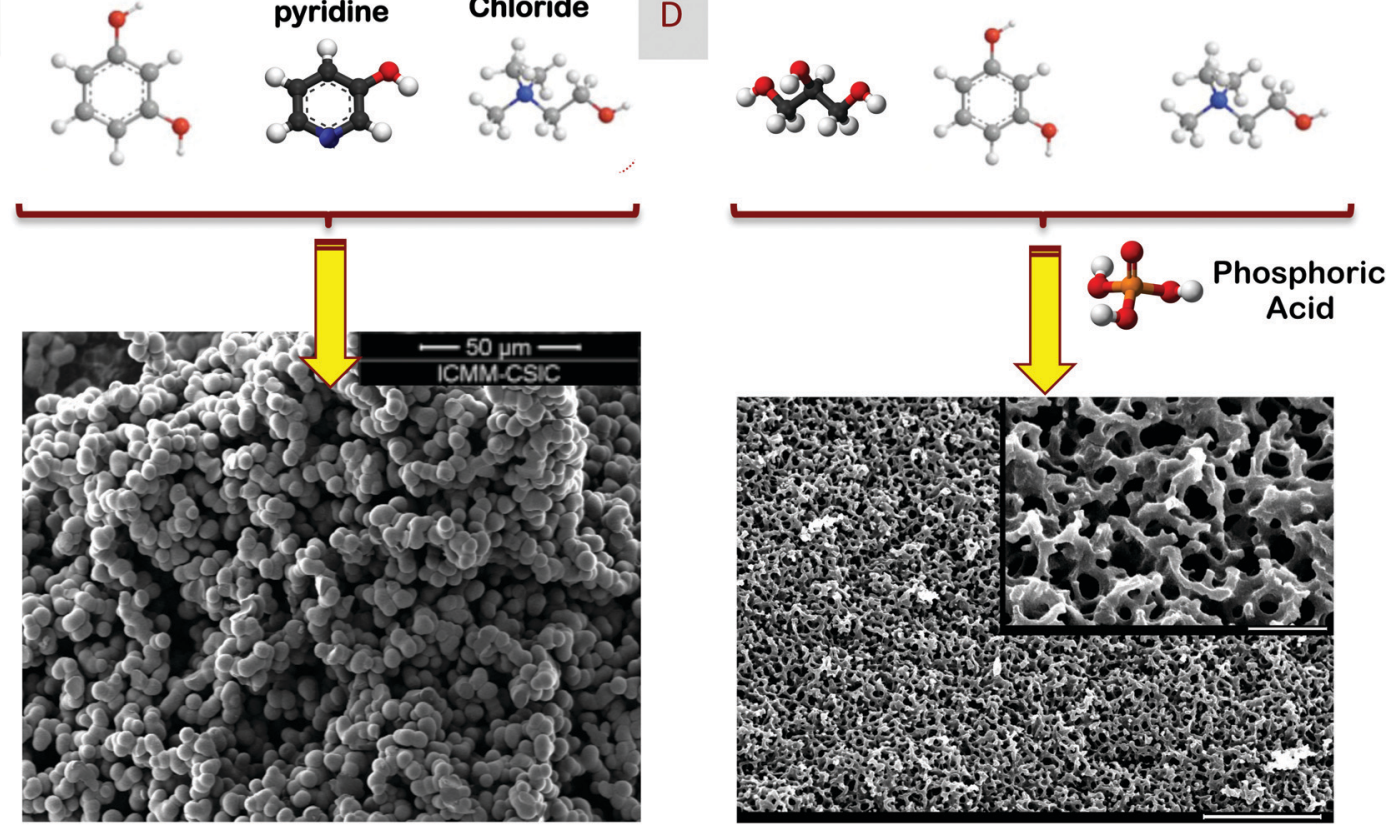

Fig. 2 Scheme representing the preparation of carbons via polycondensation of resorcinol with formaldehyde using (A) eutectic mixtures of urea, resorcinol, and $\mathrm{ChCl}$, (B) resorcinol, hexylresorcinol, and tetraethylammonium bromide, (C) resorcinol, 3-hydroxypyridine, and $\mathrm{ChCl}$, and (D) resorcinol, glycerol, and $\mathrm{ChCl}$ (in this latter case, using phosphoric acid as the catalyst). SEM micrographs of the respective carbons are also included. Adapted with permission from ref. $25 b, 43,45,46$ and 49.

(upon its participation in polycondensation reactions) so that its release during carbonization played a role in the development of micropores, i.e., the larger the molar ratio of urea in the original DES, the larger its incorporation into the RF network, and the larger the surface area developed during carbonization. With regard to the dimensions of the mesopores, the observed increase was most likely due to the capability of urea (the non-condensed one) and ChCl to form a DES by themselves, thus favoring - in terms of stability of the segregated phase - their joint segregation from the rich polymer phase during the SD process with the subsequent increase in the dimensions of the mesopores resulting after carbonization. ${ }^{44}$ Interestingly, narrow micropores could also be obtained upon the use of ternary DESs composed of resorcinol, 4-hexylresorcinol, and tetraethylammonium bromide (Fig. 2B). ${ }^{45}$ In this case, 4-hexylresorcinol not only played the role of a precursor (by co-condensation with resorcinol) but also of a SDA 
because of the presence of the long-alkyl-chain, a typical feature of many SDAs. Moreover, DESs are not only capable of providing carbons that exhibit tailored textural properties but also a significant compositional versatility. For instance, N-doped hierarchical carbons can be obtained upon the use of ternary DESs containing not only resorcinol but also nitrogen-rich precursors, e.g., 3-hydroxypyridine, 2-cyanophenol, or 4-cyanophenol (Fig. 2C). ${ }^{46-48}$ Moreover, P-doped hierarchical carbons can also be obtained upon the use of ternary DESs composed of resorcinol, glycerol, and $\mathrm{ChCl}$, and using phosphoric acid to catalyze the polycondensation so that, during carbonization, phosphoric acid functionalized the porous surface of the resulting carbons with phosphate moieties, thus obtaining P-doped or even N,P-codoped carbons (Fig. 2D). ${ }^{49,50}$ Eventually, the use of quaternary DESs containing $\mathrm{ChCl}$ (as the HBA) and resorcinol, 4-hexylresorcinol, and 4-nitrophenol (as the precursors for polycondensation) resulted in $\mathrm{N}$-doped hierarchical carbons also exhibiting a narrow microporosity; the latter one is a consequence of the presence of 4-hexylresorcinol in the starting DES and the double role it plays, i.e., as one of the carbon precursors and as SDA. ${ }^{51}$

\section{Study of aqueous dilutions of DESs}

As mentioned above, whether the mechanism followed in DESassisted polycondensation is a regular SD process starting in a liquid phase fully homogeneous at both the macro and the nanoscale was a matter of interest to us. For instance, SEM micrographs of carbons obtained from ternary DESs composed of resorcinol, glycerol, and $\mathrm{ChCl}$, and using phosphoric acid to catalyze the polycondensation revealed how the morphologies of the resulting carbons changed remarkably with the increase in mass fraction of water added, besides formaldehyde, in the DES to start the polycondensation (Fig. 3C). ${ }^{50}$ Thus, using a liquid binary mixture with $80 \mathrm{wt} \%$ of DES content as the starting solution resulted in carbons exhibiting a fine co-continuous structure (bottom row in Fig. 3C). Meanwhile, using a liquid binary mixture with $70 \mathrm{wt} \%$ of DES content as the starting solution resulted in carbons also exhibiting a co-continuous structure but with a thicker skeleton as compared to the previous ones (middle row in Fig. 3C). The SEM micrographs of these latter carbons also revealed the presence of both small spherical pores in the coarse skeleton and small particles within the open porosity that ultimately landed on the surface of the skeleton after the removal of the non-condensed matter, i.e., after drying and subsequent carbonization. The spherical pores were voids left by the solvents that, during polycondensation, separated out in the polymer-rich domain as a result of a secondary phase separation - this is, the precipitation of a secondary phase within the first separated phase when a region of this latter one is physically isolated and develops further immiscibility. ${ }^{52-54}$ Secondary phase separation may occur in the polymer phase, in the pore phase, or in both, as it was actually our case. Further increase in the mass fraction of water at the starting liquid binary mixtures provided morphologies characterized by loosely packed isolated spheres, the mean size of which became larger along with the increase in water content because of the occurrence of further particle growth for long gelation times (upper row in Fig. 3C).

The above-described results reconciled with chemically induced phase separations, e.g. , typically with the aid of a phase-separationinducing agent (PSIA), where immiscibility was observed to develop concurrently with polymerization and the ultimate morphology of the resulting polymer depends on the onset between phase separation and gel formation (Fig. 3A). In every SD process reported to date, the fluid phase resulting after the phase separation is a solvent mixture that contains the PSIA, any co-solvent that may be eventually used to help the demixing of the PSIA, and any additional compound that may result as a by-product of the reaction. ${ }^{55}$ In our particular case, the fluid phase was composed of non-polymerizable DES components, e.g., glycerol, $\mathrm{ChCl}$, phosphoric acid, and water. Glycerol, $\mathrm{ChCl}$, and phosphoric acid were originally part of DES, the rupture of which during polycondensation resulted in their segregation in the fluid phase. Regarding water, a minor fraction of it was the by-product of RF polycondensation but most of it was added at the starting homogeneous solution so as to promote/favour the phase separation. The use of water as PSIA has been rarely described in papers dealing with SD processes, ${ }^{56-59}$ despite the obvious interest that its use offers environmental and sustainable means as compared to other co-solvents more commonly used - e.g., non-friendly solvents, polymers, and/or surfactants. As described previously, ${ }^{59}$ the mass fraction of water controls the resulting morphology in terms of reaction kinetics. Thus, in diluted samples, phase separation occurred earlier than gel formation and the polymer-rich domains broke-up into spherical colloids that, afterwards, became a gel, i.e., sooner for pseudodiluted samples and later for highly diluted ones.

Despite the fact that water may indeed play the role of PSIA in regular SD processes, it is also worth discussing certain peculiarities of DES/ $\mathrm{H}_{2} \mathrm{O}$ binary mixtures. ${ }^{60}$ Most of the DES components are soluble in water or at least, they belong to the group of $\mathrm{H}$-bond-forming molecules, so it is commonly assumed that, in a highly diluted regime, DESs should be entirely miscible in the aqueous phase while, in a less diluted regime, water should be entirely miscible in the DES phase. This is at least what the homogeneity at the macroscopic scale of DES/ $\mathrm{H}_{2} \mathrm{O}$ binary mixtures suggests (Fig. 3D). However, Brillouin spectroscopy experiments revealed some interesting features in many different $\mathrm{DES} / \mathrm{H}_{2} \mathrm{O}$ binary mixtures. It is worth noting that Brillouin spectroscopy is particularly suitable for detecting the local structural rearrangements in liquid mixtures of $\mathrm{H}$-bond co-solvents ( $\mathrm{MeOH}$, EtOH, $t$-BuOH, etc.), polymers (PEG), and even hydrated salts with either water or organic solvents. ${ }^{61-70}$ In all these mixtures, the plot of hypersonic velocity $\left(v_{\mathrm{H}}\right.$, obtained from Brillouin measurements) versus the mole fraction of the co-solvent $(\chi)$ revealed the existence of deviation from the ideal behaviour. This deviation depends on the nature of the co-solvent and it is reflected in the shape plot, e.g., displaying a maximum or a minimum when the co-solvent is a small molecule, or exponentiallike when the co-solvent is a polymer, and hence, is more prone to forming a continuous H-bond network (Fig. 4). 

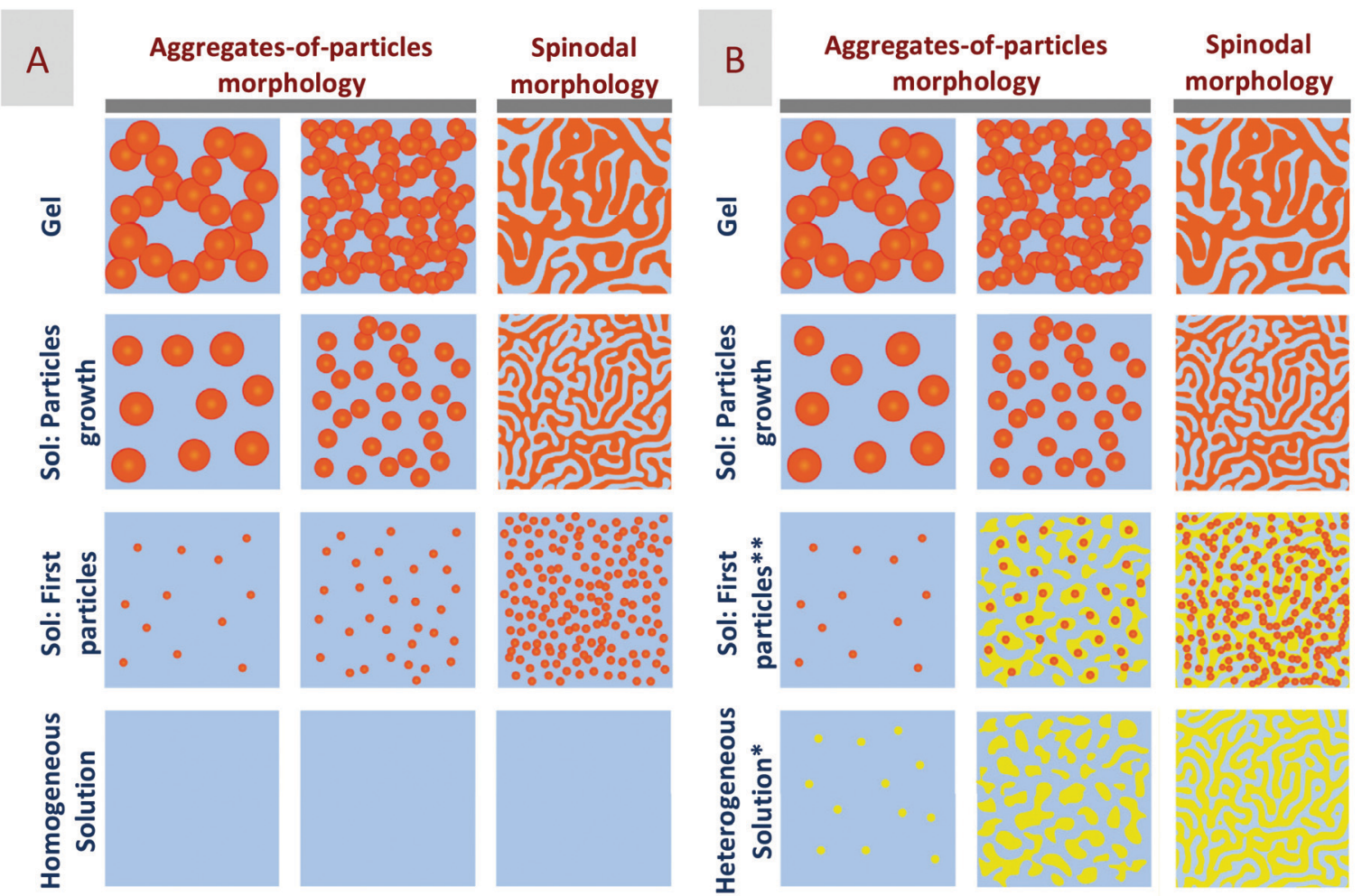

要
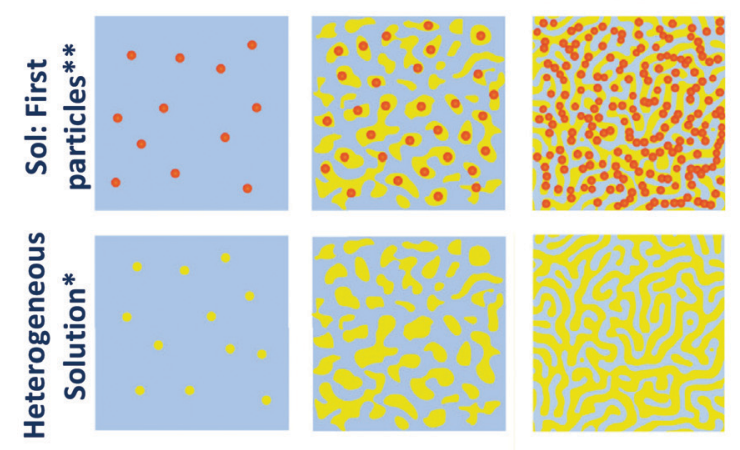

* Homogeneous at the macroscale but heterogeneous at the nanoscale

** Appearing at DES domains

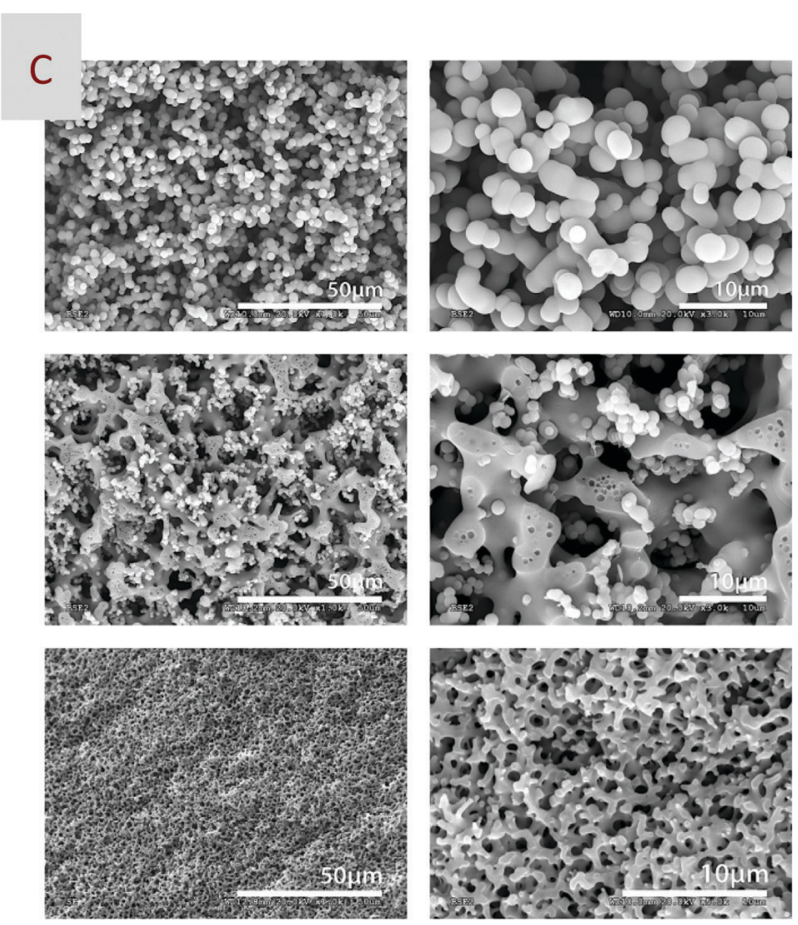

D

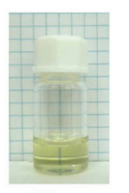

$\mathrm{DES}_{\mathrm{RPGC80}}$

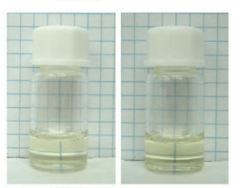

$D_{\text {DEGC60 }} \quad \mathrm{DES}_{\text {RPGC70 }}$
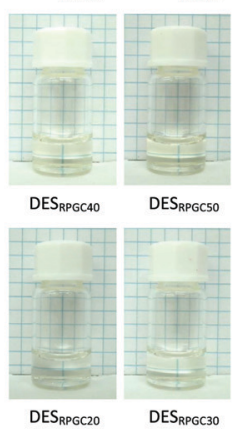
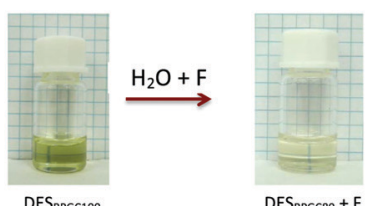

$\mathrm{DES}_{\mathrm{RPGC80}}+\mathrm{F}$

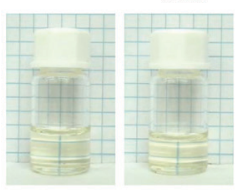

$\mathrm{DES}_{\mathrm{RPGC60}}+\mathrm{F} \quad \mathrm{DES}_{\mathrm{RPGC70}}+\mathrm{F}$
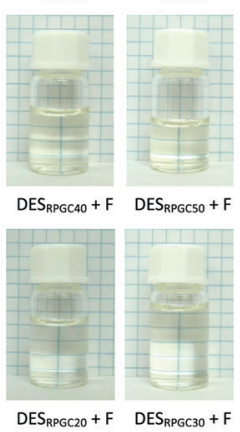

Fig. 3 Idealized scheme representing the formation of aggregates-of-particles or spinodal morphologies in (A) regular and (B) DES-assisted phase separation processes. In the latter case, first, the nucleation and growth of colloidal particles will occur preferentially at DES nanodomains rich in resorcinol so that phase separation is predetermined as compared to regular SD processes. (C) SEM micrographs of some representative carbons obtained after polycondensation of $\mathrm{DES} / \mathrm{H}_{2} \mathrm{O}$ binary mixtures with increased DES contents. (D) Picture of DES/ $\mathrm{H}_{2} \mathrm{O}$ binary mixtures with increased DES contents from top to bottom, diluted with just $\mathrm{H}_{2} \mathrm{O}$ (left) or with the aqueous dilution of formaldehyde used for polycondensation (right). Adapted with permission from ref. 50. 


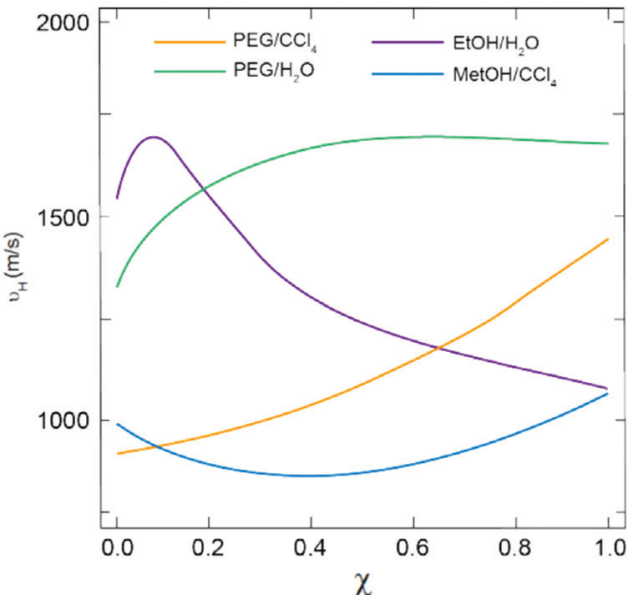

Fig. 4 Plot of hypersonic velocity versus molar fraction of the co-solvent for different binary mixtures. Reprinted with permission from ref. 50 .
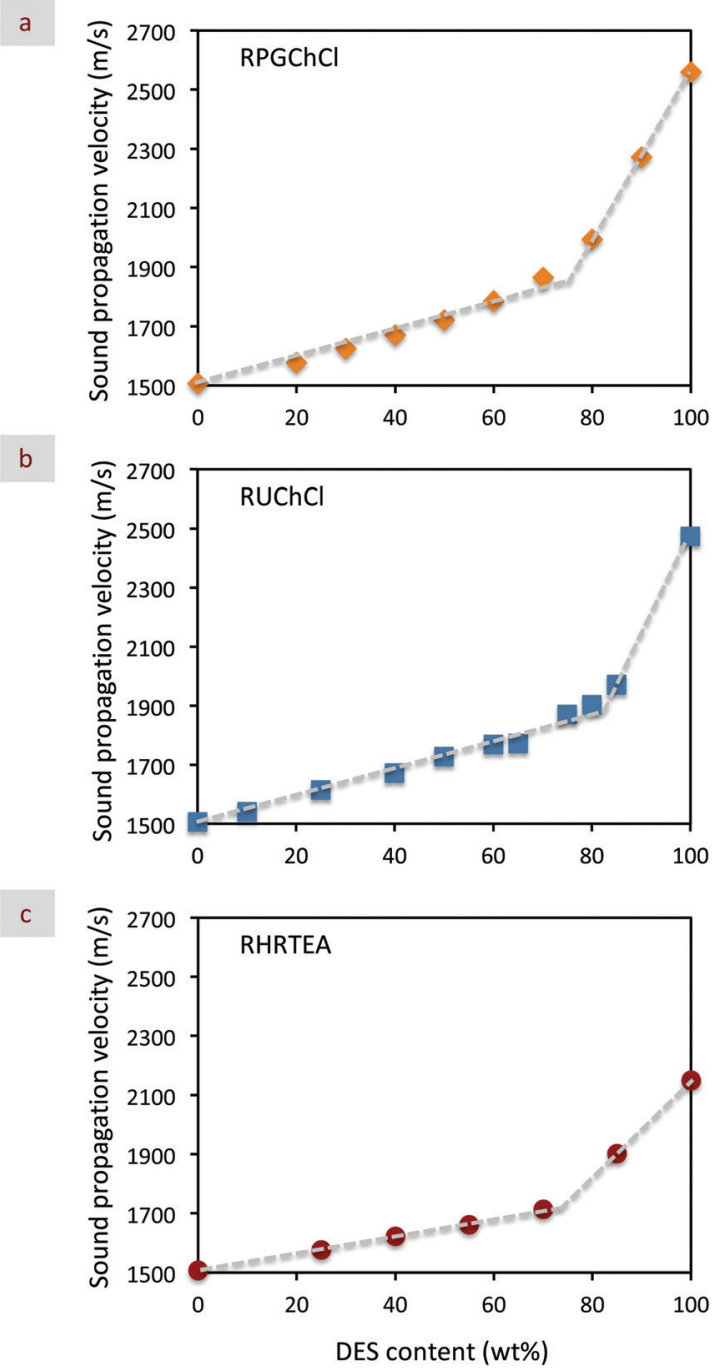

Fig. 5 Plot of sound propagation velocity - e.g., as obtained by Brillouin spectroscopy carried out at $25{ }^{\circ} \mathrm{C}$ - versus DES content (in wt\%) of aqueous dilutions of different DESs - e.g., (a) RPGChCl, (b) $\mathrm{RUChCl}$, and (c) RHRTEA. Adapted with permission from ref. 50, 72 and 78.
In the particular case of DES $/ \mathrm{H}_{2} \mathrm{O}$ binary mixtures, e.g., DESs composed of resorcinol, phosphoric acid, glycerol, and $\mathrm{ChCl}$ (RPGC), ${ }^{50}$ DESs composed of resorcinol, urea and $\mathrm{ChCl}(\mathrm{RUChCl}){ }^{78}$ and DES composed of resorcinol, 4-hexylresorcinol, and tetraethylammonium bromide, (RHRTEA), ${ }^{72}$ the representation of $\nu_{\mathrm{H}}$ versus DES content in wt $\%$ provided an even more illustrative display of the deviation with two well-distinguishable regions when transitioning from the $v_{\mathrm{H}}$ of neat $\mathrm{H}_{2} \mathrm{O}-$ e.g., ca. $1460 \mathrm{~m} \mathrm{~s}^{-1}$ - to that of neat DES (Fig. 5). Thus, in the region of low DES contents so called the "DES-in-water" system, $v_{\mathrm{H}}$ values were close or just slightly above those of $\mathrm{H}_{2} \mathrm{O}$, most likely as a consequence of propagation through a continuous $\mathrm{H}$-bond network of $\mathrm{H}_{2} \mathrm{O}$. Meanwhile, above a certain threshold value of DES content, $v_{\mathrm{H}}$ values approached those of neat DES in a quicker fashion as a consequence of the coalescence of DES domains into a continuous network structure so called the "water-in-DES" system. Thus, at the transition from one regime to the other, one could hypothesize about the formation of a co-continuous structure as a consequence of demixing and nanostructural rearrangements between DES and water domains occurring at or near this threshold value.

The evolution along with dilution of the self-diffusion coefficients of DES components as well as of water in different DES dilutions also confirmed the presence of two well-distinguishable regions transitioning from one to the other at DES contents similar
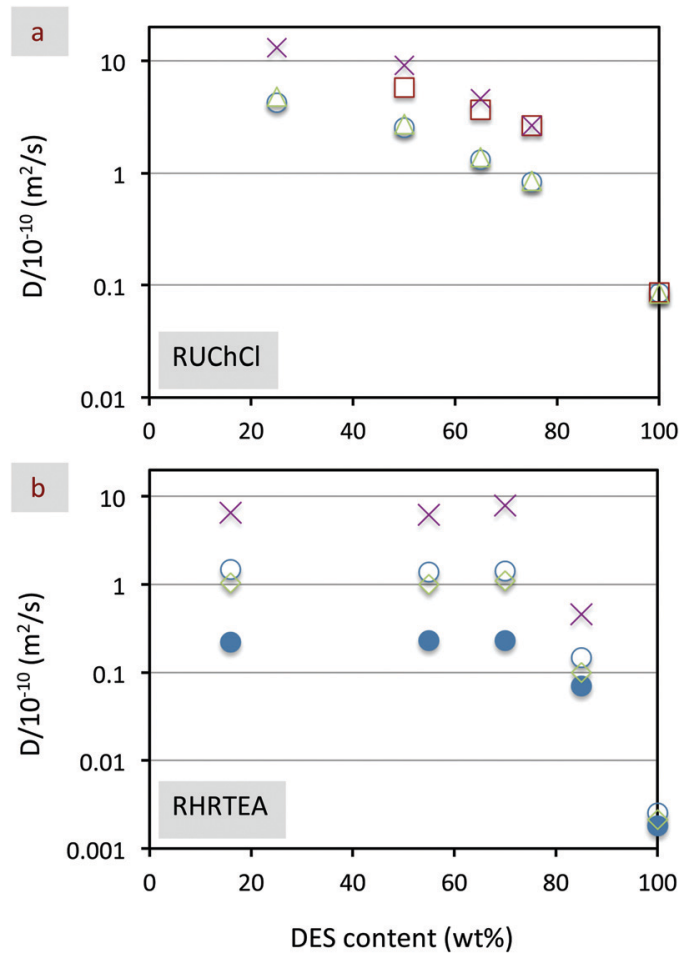

Fig. 6 Plot of self-diffusion coefficients - e.g., as obtained by NMR spectroscopy carried out at $25{ }^{\circ} \mathrm{C}$ - versus DES content (in wt\%) of aqueous dilutions of different DESs - e.g., (a) RUChCl and (b) RHRTEA. Resorcinol data are blue open circles, 4-hexylresorcinol data are blue solid circles, urea data are red open squares, $\mathrm{ChCl}$ data are green open triangles. tetraethylammonium bromide data are green open diamonds, and $\mathrm{H}_{2} \mathrm{O}$ data are purple crosses. Adapted with permission from ref. 72 and 78. 
to those found from Brillouin spectroscopy, i.e., $85 \mathrm{wt} \%$ for RUChCl and 75 wt\% for RHRTEA (Fig. 6).

Both the "DES-in-water" and the "water-in-DES" with low water contents - e.g., one or two moles of water per mole of DES systems have been widely studied and agreement exists with regard to their respective natures - e.g., a simple aqueous dilution of the individual DES components in the former case ${ }^{73,74}$ or water playing the role of a second small HBD in the latter one. ${ }^{75-77}$ However, less agreement exists with regard to the nature of intermediate dilutions; this is the "water-in-DES" system with high water contents where the water fraction is yet too low to promote the DES rupture and dissolve its components. Interestingly, in a recent work dealing with pseudo-concentrated aqueous solutions of DES composed of resorcinol, urea, and $\mathrm{ChCl}$, we demonstrated that water played the role of an additional HBD or HBA and, hence, was interstitially accommodated within the DES-based 3D H-bonded network, thus forming the "water-in-DES" system. ${ }^{78}$ Moreover, the phase behaviour of aqueous solutions of ethaline has been recently described. ${ }^{79}$

The achievement of new eutectic mixtures with significant water contents is indeed of relevance in practical applications as we may preserve and even improve some of the most interesting features of DESs such as low melting points (Fig. 7) and overcome some other important drawbacks. For instance, the aqueous DES dilution of RUChCl with a water-to-DES molar ratio of 11:1 exhibited a melting point as low as ca. $-20{ }^{\circ} \mathrm{C}$ (Fig. 7) and a viscosity reduction of more than 10 -fold as compared to that of the neat DES - e.g., from ca. 37.6 to ca. $2.8 \mathrm{cP}$ at $80{ }^{\circ} \mathrm{C}$. The addition of water to other DESs such as reline and malicine also resulted in a decrease in the melting point of the original DES (Fig. 7). ${ }^{78}$ Interestingly, all the $\mathrm{DES} / \mathrm{H}_{2} \mathrm{O}$ binary mixtures with melting points at the lowest temperature were those with water contents where the plot of $v_{\mathrm{H}}$ versus DES content obtained by Brillouin spectroscopy deviated from linearity (Fig. 5b). ${ }^{71,77,78}$
$\mathrm{RUChCl}$
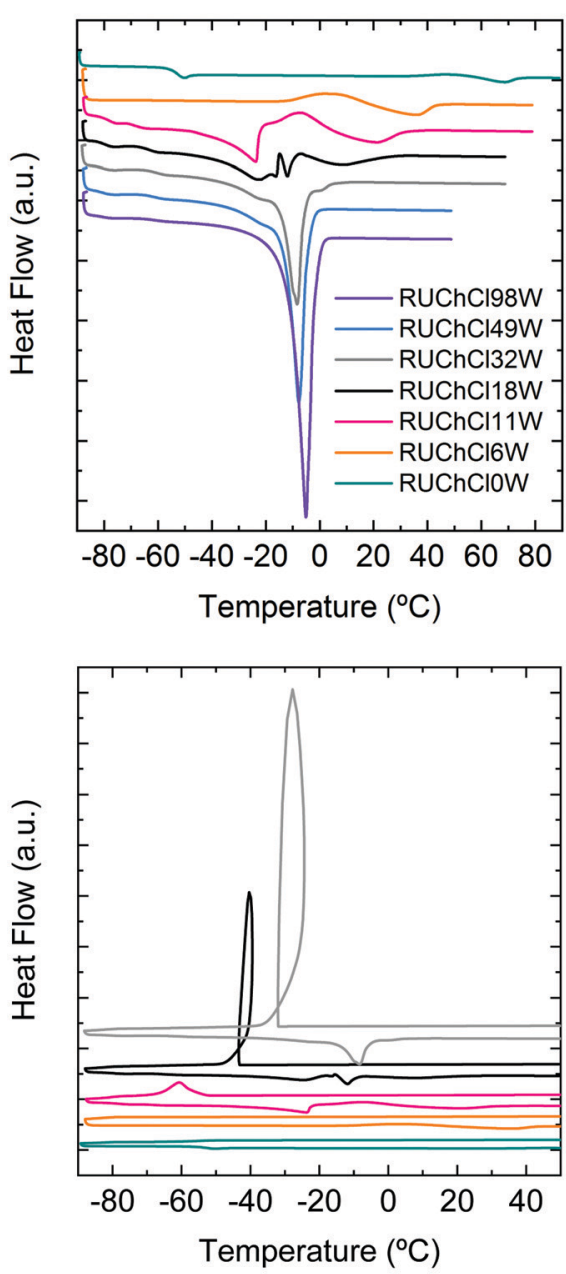

Reline
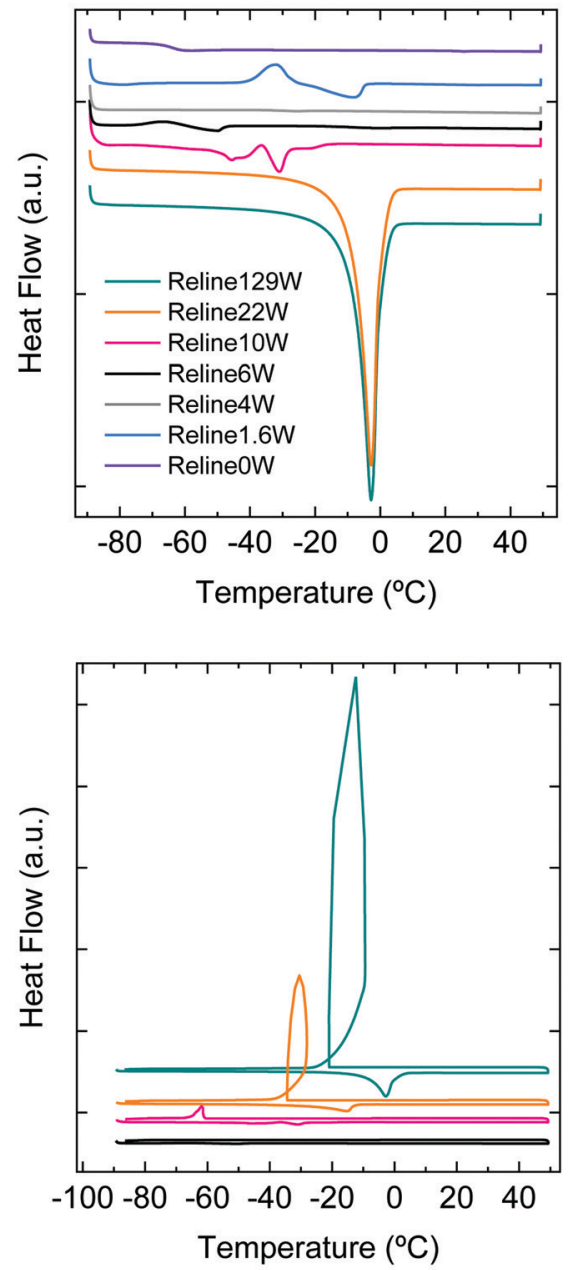

Malicine
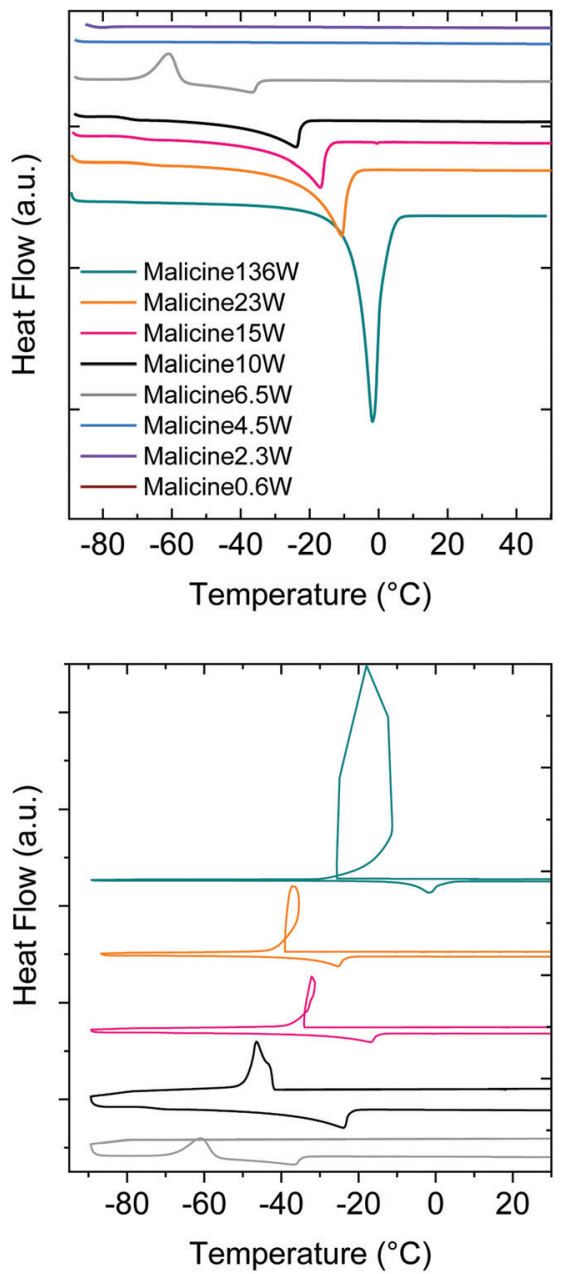

Fig. 7 DSCs scans (heating ramp in upper panel; heating and cooling ramp in lower one) of aqueous dilutions of different DESs - e.g., RUChCl in left column, reline (a DES composed of urea and $\mathrm{ChCl}$ in a $2: 1$ molar ratio) in middle column and malicine (a DES composed of malic acid and ChCl in a 1:1 molar ratio). In $\mathrm{RUChCl}_{n} \mathrm{~W}$, reline $\mathrm{W}_{n}$ and malicine ${ }_{n} \mathrm{~W}, n$ represents the $\mathrm{H}_{2} \mathrm{O}$ to DES molar ratio. Reprinted with permission from ref. 78 . 


\section{Future directions and outlook}

We would like to end this featured article mentioning that the use of DESs in materials synthesis is still rare as compared to ILs, although ILs can still be considered in their infancy as well. Future work should extend the use of "all-in-one" DESs to other polymerizations. For instance, ring-opening polymerizations for the preparation of poly( $\varepsilon$-caprolactone $)^{80}$ and poly(L-lactide)/ poly( $\varepsilon$-caprolactone) blends ${ }^{81}$ oxidative polymerizations for the preparation of conductive, ${ }^{7,82}$ and semiconductive ${ }^{83}$ polymers or atom transfer radical polymerization using metal-ligand compounds as catalysts ${ }^{84}$ are fields of tremendous relevance where DES contribution is still in its infancy. Moreover, establishing a clear parallelism with the challenges of ILs in the synthesis of chiral MOFs and zeolites, ${ }^{85}$ the use of chiral DESs capable of chiral induction into the synthesized material is also quite a relevant field. ${ }^{86}$ Given the wide number of molecules that can be used for the preparation of DESs, exploring a wide range of chiral ones that can be suitable for the accomplishment of this target seems an attainable objective. Moreover, one could envisage the design of future synthetic strategies of COFs and POFs based on the use of "all-in-one" DESs, in which one of the components acts as the precursor and becomes a part of the network structure while the other one acts as the guest molecule. The easy incorporation of guest molecules provided by the use of "all-in-one" DESs also opens interesting perspectives in the field of biomedicine. It is worth reminding that DESs offer the advantage of being prepared from compounds of known toxicity and could even be in current clinical use. Finally, the virtually unlimited flexibility of combinations of mixtures that can be used for DES preparation should allow the further tailoring of properties within the family of the herein described carbon materials as well as for the preparation of novel carbon materials performing well as adsorbents in sustainable applications - e.g., $\mathrm{CO}_{2}$ adsorption and separation - and as electrodes in energy storage devices - e.g., batteries and supercapacitors. It is also worth noting the relevance of the study of aqueous DESs, originally performed with the aim of understanding the formation mechanism of the porous structure of carbon materials but finally revealing the possibility of obtaining new eutectic mixtures upon the simple addition of water to DESs while keeping the $\mathrm{DES} / \mathrm{H}_{2} \mathrm{O}$ contents within the "water-inDES" regime. The low viscosity and low melting point of these aqueous eutectics - more so than those of the original eutectic mixture - open interesting perspectives in practical applications, thus providing a novel field of research for DESs.

\section{Conflicts of interest}

There are no conflicts to declare.

\section{Acknowledgements}

This work was supported by MINECO/FEDER (Project Numbers MAT2015-68639-R, RTI2018-096918-B-C41 and RTI2018-097728B-I00). Comunidad de Madrid and Kleinscale Inc. are also acknowledged for sponsoring G. C.-H.'s PhD fellowship.

\section{References}

1 (a) C. Reichardt, Solvents and Solvent Effects in Organic Chemistry, Wiley-VCH, Weinheim, Germany, 3rd edn, 2003; (b) C.-P. Li and $\mathrm{M}$. Du, Role of solvents in coordination supramolecular systems, Chem. Commun., 2011, 47, 5958-5972.

2 A. P. Abbott, G. Capper, D. L. Davies, R. K. Rasheed and V. Tambyrajah, Novel solvent properties of choline chloride/urea mixtures, Chem. Commun., 2003, 70-71.

3 G. Garcia, M. Atilhan and S. Aparicio, An approach for the rationalization of melting temperature for deep eutectic solvents from DFT, Chem. Phys. Lett., 2015, 634, 151-155.

4 S. Zahn, B. Kirchner and D. Mollenhauer, Charge Spreading in Deep Eutectic Solvents, ChemPhysChem, 2016, 17, 3354-3358.

5 C. R. Ashworth, R. P. Matthews, T. Welton and P. A. Hunt, Doubly ionic hydrogen bond interactions within the choline chloride-urea deep eutectic solvent, Phys. Chem. Chem. Phys., 2016, 18, 18145-18160.

6 O. S. Hammond, D. T. Bowron and K. J. Edler, Liquid Structure of the Choline Chloride-Urea Deep Eutectic Solvent (reline) from Neutron Diffraction and Atomistic Modelling, Green Chem., 2016, 18, 18145-18160.

7 O. S. Hammond and K. J. Edler, in Deep Eutectic Solvents: Synthesis, Properties, and Applications, ed. D. J. Ramón and G. Guillena, WileyVCH Verlag GmbH \& Co. KGaA, 2020, ch. 2, pp. 25-42.

8 C. F. Araujo, J. A. P. Coutinho, M. M. Nolasco, S. F. Parker, P. J. A. Ribeiro-Claro, S. Rudić, B. I. G. Soares and P. Vaz, Inelastic neutron scattering study of reline: shedding light on the hydrogen bonding network of deep eutectic solvents, Phys. Chem. Chem. Phys., 2017, 19, 17998-18009.

9 (a) A. P. Abbott, D. Boothby, G. Capper, D. L. Davies and R. K. Rasheed, Deep Eutectic Solvents Formed between Choline Chloride and Carboxylic Acids: Versatile Alternatives to Ionic Liquids, J. Am. Chem. Soc., 2004, 126, 9142-9147; (b) C. A. Nkuku and R. J. LeSuer, Electrochemistry in Deep Eutectic Solvents, J. Phys. Chem. B, 2007, 111, 13271-13277; (c) A. P. Abbott, R. C. Harris and K. S. Ryder, Application of Hole Theory to Define Ionic Liquids by their Transport Properties, J. Phys. Chem. B, 2007, 111, 4910-4913; (d) A. P. Abbott, G. Capper and S. Gray, Design of Improved Deep Eutectic Solvents Using Hole Theory, ChemPhysChem, 2006, 7, 803-806; (e) M. A. Kareem, F. S. Mjalli, M. A. Hashim and I. M. AlNashef, Phosphonium-Based Ionic Liquids Analogues and Their Physical Properties, J. Chem. Eng. Data, 2010, 55, 4632-4637; ( $f$ ) K. Shahbaz, F. S. Mjalli, M. A. Hashim and I. M. AlNashef, Prediction of deep eutectic solvents densities at different temperatures, Thermochim. Acta, 2011, 515, 67-72; ( $g$ ) A. P. Abbott, J. C. Barron, K. S. Ryder and D. Wilson, Eutectic-Based Ionic Liquids with Metal-Containing Anions and Cations, Chem. - Eur. J., 2007, 13, 6495-6501; (h) N. S. V. Narayanan, B. V. A. Raj and S. Sampath, Ambient temperature, zinc ion-conducting, binary molten electrolyte based on acetamide and zinc perchlorate: Application in rechargeable zinc batteries, J. Colloid Interface Sci., 2010, 342, 505-512; (i) N. S. V. Narayanan, B. V. A. Raj and S. Sampath, Magnesium ion conducting, room temperature molten electrolytes, Electrochem. Commun., 2009, 11, 2027-2031; $(j)$ N. S. V. Narayanan, B. V. A. Raj and S. Sampath, Physicochemical, spectroscopic and electrochemical characterization of magnesium ion-conducting, room temperature, ternary molten electrolytes, J. Power Sources, 2010, 195, 4356-4364; $(k)$ H. Zhao, G. A. Baker and S. Holmes, New eutectic ionic liquids for lipase activation and enzymatic preparation of biodiesel, Org. Biomol. Chem., 2011, 9, 1908-1916; (l) Y. H. Choi, J. van Spronsen, Y. Dai, M. Verberne, F. Hollmann, I. W. C. E. Arends, G.-J. Witkamp and R. Verpoorte, Are Natural Deep Eutectic Solvents the Missing Link in Understanding Cellular Metabolism and Physiology?, Plant Physiol., 2011, 156, 1701-1705; $(m)$ U. S. Rai and R. N. Rai, Physical Chemistry of Organic Eutectics, J. Therm. Anal., 1998, 53, 883-893; (n) S. Gore, S. Baskaran and B. Koenig, Efficient synthesis of 3,4-dihydropyrimidin-2-ones in low melting tartaric acid-urea mixtures, Green Chem., 2011, 13, 1009-1013; (o) P. W. Stott, A. C. Williams and B. W. Barry, Transdermal delivery from eutectic systems: enhanced permeation of a model drug, ibuprofen, J. Controlled Release, 1998, 50, 297-308.

10 Among others: (a) P.-C. Jhang, N.-T. Chuang and S.-L. Wang, Layered Zinc Phosphates with Photoluminescence and Photochromism: Chemistry in Deep Eutectic Solvents, Angew. Chem., Int. Ed., 2010, 49, 4200-4204; (b) S.-M. Wang, W.-L. Chen, E.-B. Wang, Y.-G. Li, 
X.-J. Feng and L. Liu, Three new polyoxometalate-based hybrids prepared from choline chloride/urea deep eutectic mixture at room temperature, Inorg. Chem. Commun., 2010, 13, 972-975; (c) J. Zhang, $\mathrm{T}$. Wu, S. Chen, P. Feng and X. Bu, Versatile Structure-Directing Roles of Deep-Eutectic Solvents and Their Implication in the Generation of Porosity and Open Metal Sites for Gas Storage, Angew. Chem., Int. Ed., 2009, 48, 3486-3490; (d) E. R. Parnham, E. A. Drylie, P. S. Wheatley, A. M. Z. Slawin and R. E. Morris, Ionothermal Materials Synthesis Using Unstable Deep-Eutectic Solvents as Template-Delivery Agents, Angew. Chem., Int. Ed., 2006, 45, 4962-4966; (e) E. A. Drylie, D. S. Wragg, E. R. Parnham, P. S. Wheatley, A. M. Z. Slawin, J. E. Warren and R. E. Morris, Ionothermal Synthesis of Unusual Choline-Templated Cobalt Aluminophosphates, Angew. Chem., Int. Ed., 2007, 46, 7839-7843; $(f)$ S. Chen, J. Zhang, T. Wu, P. Feng and X. Bu, Zinc(II)-boron(III)-imidazolate framework (ZBIF) with unusual pentagonal channels prepared from deep eutectic solvent, Dalton Trans., 2010, 39, 697-699.

11 Y. Zhao, Y. Zhao, H. Feng and J. Shen, Synthesis of nickel phosphide nano-particles in a eutectic mixture for hydrotreating reactions, J. Mater. Chem., 2011, 21, 8137-8145.

12 A. Querejeta-Fernández, M. Parras, A. Varela, F. del Monte, M. García-Hernández and J. M. González-Calbet, Urea-melt assisted synthesis of $\mathrm{Ni} / \mathrm{NiO}$ nanoparticles exhibiting structural disorder and exchange bias, Chem. Mater., 2010, 22, 6529-6541.

13 (a) K. Dhanalakshmi, R. Saraswathi and C. Srinivasan, Synthesis and electrochemical stability of polyaniline and polypyrrole in an ambient temperature acetamide-urea-ammonium nitrate eutectic melt, Synth. Met., 1996, 82, 237-243; (b) P. S. Abthagir and R. Saraswathi, Thermal stability of polypyrrole prepared from a ternary eutectic melt, Mater. Chem. Phys., 2005, 92, 21-26.

14 D. Mondal, M. Sharma, C.-H. Wang, Y.-C. Lin, H.-C. Huang, A. Saha, S. K. Nataraj and K. Prasad, Deep eutectic solvent promoted one step sustainable conversion of fresh seaweed biomass to functionalized graphene as a potential electrocatalyst, Green Chem., 2016, 18, 2819-2826.

15 J. P. Paraknowitsch, J. Zhang, D. Su, A. Thomas and M. Antonietti, Ionic Liquids as Precursors for Nitrogen-Doped Graphitic Carbon, Adv. Mater., 2010, 22, 87-92.

16 D. A. Alonso, A. Baeza, R. Chinchilla, G. Guillena, I. M. Pastor and D. J. Ramón, Deep Eutectic Solvents: The Organic Reaction Medium of the Century, Eur. J. Org. Chem., 2016, 612-632.

17 B. B. Khanukaev, M. A. Kozhushner, N. S. Enikolopyan and N. M. Chechilo, Theory of the propagation of a polymerization front, Combust., Explos. Shock Waves, 1974, 10, 17-21.

18 (a) J. A. Pojman, V. M. Ilyashenko and A. M. Khan, Free-radical frontal polymerization: self-propagating thermal reaction waves, J. Chem. Soc., Faraday Trans., 1996, 92, 2825-2837; (b) J. A. Pojman, Traveling fronts of methacrylic acid polymerization, J. Am. Chem. Soc., 1991, 113, 6284-6286; (c) J. A. Pojman, R. Craven, A. Khan and W. West, Convective instabilities in traveling fronts of addition polymerization, J. Phys. Chem., 1992, 96, 7466-7472.

19 (a) D. I. Fortenberry and J. A. Pojman, Solvent-Free Synthesis of Polyacrylamide by Frontal Polymerization, J. Polym. Sci., Part A: Polym. Chem., 2000, 38, 1129-1135; (b) L. Chen, T. Hu, H. Yu, S. Chen and J. A. Pojman, First solvent-free synthesis of poly(N-methylolacrylamide) via frontal free-radical polymerization, J. Polym. Sci., Part A: Polym. Chem., 2007, 45, 4322-4330.

20 R. P. Washington and O. Steinbock, Frontal polymerization synthesis of temperature-sensitive hydrogels, J. Am. Chem. Soc., 2001, 123, 7933-7934.

21 (a) O. Winther-Jensen, R. Vijayaraghavan, J. Sun, B. Winther-Jensen and D. R. MacFarlane, Self polymerising ionic liquid gel, Chem. Commun., 2009, 3041-3043; (b) A. Mariani, D. Nuvoli, V. Alzari and M. Pini, Phosphonium-based ionic liquids as a new class of radical initiators and their use in gas-free frontal polymerization, Macromolecules, 2008, 41, 5191-5196.

22 (a) Z. Jiménez, C. Bounds, C. E. Hoyle, A. B. Lowe, H. Zhou and J. A. Pojman, Photopolymerization kinetics of ionic liquid monomers derived from the neutralization reaction between trialkylamines and acid-containing (meth)acrylates, J. Polym. Sci., Part A: Polym. Chem., 2007, 45, 3009-3021; (b) H. Zhou, Z. Jiménez, J. A. Pojman, M. S. Paley and C. E. Hoyle, Photopolymerization kinetics of tributylmethylammoniumbased (meth)acrylate ionic liquids and the effect of water, J. Polym. Sci., Part A: Polym. Chem., 2008, 46, 3766-3773.
23 Z. Jiménez and J. A. Pojman, Frontal polymerization with monofunctional and difunctional ionic liquid monomers, J. Polym. Sci., Part A: Polym. Chem., 2007, 45, 2745-2754.

24 (a) J. D. Mota-Morales, M. C. Gutiérrez, I. C. Sánchez, G. Luna-Bárcenas and F. del Monte, Frontal polymerizations carried out in deep-eutectic mixtures providing both the monomers and the polymerization medium, Chem. Commun., 2011, 47, 5328-5330; (b) J. D. Mota-Morales, M. C. Gutiérrez, M. L. Ferrer, I. C. Sánchez, J. Pojman, F. del Monte and G. Luna-Bárcenas, Deep Eutectic Solvents as Both Active Fillers and Monomers for Frontal Polymerization, J. Polym. Sci., Polym. Phys. Ed., 2013, 51, 1767-1773; (c) J. D. Mota-Morales, M. C. Gutiérrez, M. L. Ferrer, R. Jiménez, P. Santiago, I. C. Sánchez, M. Terrones, F. del Monte and G. Luna-Bárcenas, Synthesis of macroporous poly(acrylic acid)-carbon nanotube composites by frontal polymerization in deep-eutectic solvents, J. Mater. Chem. A, 2013, 1, 3970-3976.

25 (a) D. Carriazo, M. C. Serrano, M. C. Gutierrez, M. L. Ferrer and F. del Monte, Deep-eutectic solvents playing multiple roles in the synthesis of polymers and related materials, Chem. Soc. Rev., 2012, 41, 4996-5014; (b) F. del Monte, D. Carriazo, M. C. Serrano, M. C. Gutierrez and M. L. Ferrer, Deep Eutectic Solvents in Polymerizations: A Greener Alternative to Conventional Syntheses, ChemSusChem, 2014, 7, 999-1009.

26 (a) M. C. Serrano, M. C. Gutiérrez, M. L. Ferrer and F. del Monte, Synthesis of novel lidocaine-releasing poly(diol-co-citrate) elastomers by using deep eutectic solvents, Chem. Commun., 2012, 48, 579-581; (b) S. García-Argüelles, M. C. Serrano, M. C. Gutiérrez, M. L. Ferrer, L. Yuste, F. Rojo and F. del Monte, Deep eutectic solvent-assisted synthesis of biodegradable polyesters with antibacterial properties, Langmuir, 2013, 25, 5509-5515.

27 (a) J. Yang, A. R. Webb and G. A. Ameer, Novel Citric Acid-Based Biodegradable Elastomers for Tissue Engineering, Adv. Mater., 2004, 16, 511-516; (b) J. Yang, A. R. Webb, S. J. Pickerill, G. Hageman and G. A. Ameer, Synthesis and evaluation of poly(diol citrate) biodegradable elastomer, Biomaterials, 2006, 27, 1889-1898.

28 For instance: (a) M. C. Serrano, L. Carbajal and G. A. Ameer, Novel biodegradable shape-memory elastomers with drug-releasing capabilities, Adv. Mater., 2011, 23, 2211-2215; (b) X. Q. Zhang, H. Tang, R. Hoshi, L. de Laporte, H. Qiu, X. Xu, L. D. Shea and G. A. Ameer, Sustained transgene expression via citric acid-based polyester elastomers, Biomaterials, 2009, 30, 2632-2641.

29 (a) C. Fu and Z. Liu, Syntheses of high molecular weight aliphatic polyesters in 1-alkyl-3-methylimidazolium ionic liquids, Polymer, 2008, 49, 461-466; (b) E.-M. Dukuzeyezu, H. Lefebvre, M. Tessier and A. Fradet, Synthesis of high molar mass poly(12-hydroxydodecanoic acid) in Brønsted acid ionic liquids, Polymer, 2010, 51, 1218-1221; (c) M. Lee, U. H. Choi, D. Salas-de la Cruz, A. Mittal, K. I. Winey, R. H. Colby and H. W. Gibson, Imidazolium Polyesters: Structure-Property Relationships in Thermal Behavior, Ionic Conductivity, and Morphology, Adv. Funct. Mater., 2011, 21, 708-717; (d) S. Mallakpour, F. Tirgir and M. R. Sabzalian, Synthesis, characterization and in vitro antimicrobial and biodegradability study of pseudo-poly(amino acid)s derived from $N, N$-(pyromellitoyl)bis---tyrosine dimethyl ester as a chiral bioactive diphenolic monomer, Amino Acids, 2011, 40, 611-621.

$30 \mathrm{~J}$. Le Bideau, L. Viau and A. Vioux, Ionogels, ionic liquid based hybrid materials, Chem. Soc. Rev., 2011, 40, 907-925.

31 W. L. Hough, M. Smiglak, H. Rodriguez, R. P. Swatloski, S. K. Spear, D. T. Daly, J. Pernak, J. E. Grisel, R. D. Carliss, M. D. Soutullo, J. H. Davis Jr. and R. D. Rogers, The third evolution of ionic liquids: Active pharmaceutical ingredients, New J. Chem., 2007, 31, 1429-1436.

32 J. Stoimenovski, D. R. MacFarlane, K. Bica and R. D. Rogers, Crystalline vs. ionic liquid salt forms of active pharmaceutical ingredients: A position paper, Pharm. Res., 2010, 27, 521-526.

33 K. Bica, J. Shamshina, W. L. Hough, D. R. MacFarlane and R. D. Rogers, Liquid forms of pharmaceutical co-crystals: exploring the boundaries of salt formation, Chem. Commun., 2011, 47, 2267-2269.

34 K. Bica and R. D. Rogers, Confused ionic liquid ions - A "liquification" and dosage strategy for pharmaceutically active salts, Chem. Commun., 2010, 46, 1215-1217.

35 M. C. Gutiérrez, D. Carriazo, A. Tamayo, R. Jiménez, F. Picó, J. M. Rojo, M. L. Ferrer and F. del Monte, Deep Eutectic Solvents Assisted Synthesis of Hierarchical Carbon Electrodes Exhibiting Capacitance Retention at High Current Densities, Chem. - Eur. J., 2011, 17, 10533-10537. 
36 N. López-Salas, F. del Monte, A. Tamayo, J. L. G. Fierro, A. L. De Lacey, M. L. Ferrer and M. C. Gutiérrez, Sulfur-Doped Carbons Prepared from Eutectic Mixtures Containing Hydroxymethylthiophene as Metal-Free Oxygen Reduction Catalysts, ChemSusChem, 2014, 7, 3347-3355.

37 J. Patiño, N. López-Salas, M. C. Gutiérrez, D. Carriazo, M. L. Ferrer and F. del Monte, Phosphorus-doped carbon-carbon nanotube hierarchical monoliths as true three-dimensional electrodes in supercapacitor cells, J. Mater. Chem. A, 2016, 4, 1251-1263.

38 L. Z. Guan, J. Patiño, C. Cuadrado-Collados, A. Tamayo, M. C. Gutiérrez, M. L. Ferrer, J. Silvestre-Albero and F. del Monte, Carbon-GO Composites with Preferential Water versus Ethanol Uptake, ACS Appl. Mater. Interfaces, 2019, 11, 24493-24503.

39 R. W. Pekala, Organic aerogels from the polycondensation of resorcinol with formaldehyde, J. Mater. Sci., 1989, 24, 3221.

40 A. Taguchi, J.-H. Smatt and M. Lindén, Carbon Monoliths Possessing a Hierarchical, Fully Interconnected Porosity, Adv. Mater., 2003, 15, 1209.

41 S. A. Al-Muhtaseb and J. A. Ritter, Preparation and Properties of Resorcinol-Formaldehyde Organic and Carbon Gels, Adv. Mater., 2003, 15, 101.

42 (a) Y. Zhai, Y. Dou, D. Zhao, P. F. Fulvio, R. T. Mayes and S. Dai, Carbon materials for chemical capacitive energy storage, Adv. Mater., 2011, 9, 4828-4850; (b) J. Biener, M. Stadermann, M. Suss, M. A. Worsley, M. M. Biener, K. A. Rose and T. F. Baumann, Advanced carbon aerogels for energy applications, Energy Environ. Sci., 2011, 4, 656-667.

43 D. Carriazo, M. C. Gutiérrez, M. L. Ferrer and F. del Monte, Resorcinol-Based Deep Eutectic Solvents as Both Carbonaceous Precursors and Templating Agents in the Synthesis of Hierarchical Porous Carbon Monoliths, Chem. Mater., 2010, 22, 6146-6152.

44 N. López-Salas, D. Carriazo, M. C. Gutiérrez, M. L. Ferrer, C. O. Ania, F. Rubio, A. Tamayo, J. L. G. Fierro, M. L. Ferrer and F. del Monte, Tailoring the textural properties of hierarchical porous carbons using deep eutectic solvents, J. Mater. Chem. A, 2016, 4, 9146-9159.

45 J. Patiño, M. C. Gutiérrez, D. Carriazo, C. O. Ania, J. L. Parra, M. L. Ferrer and F. del Monte, Deep eutectic assisted synthesis of carbon adsorbents highly suitable for low-pressure separation of $\mathrm{CO}_{2}-\mathrm{CH}_{4}$ gas mixtures, Energy Environ. Sci., 2012, 5, 8699-8707.

46 M. C. Gutiérrez, D. Carriazo, C. O. Ania, J. L. Parra, M. L. Ferrer and F. del Monte, Deep Eutectic Solvents as Both Precursors and Structure Directing Agents in the Synthesis of Nitrogen Doped Hierarchical Carbons Highly Suitable for $\mathrm{CO}_{2}$ Capture, Energy Environ. Sci., 2011, 4, 4201-4210.

47 J. Patiño, M. C. Gutiérrez, D. Carriazo, C. O. Ania, J. L. G. Fierro, M. L. Ferrer and F. del Monte, DES assisted synthesis of hierarchical nitrogen-doped carbon molecular sieves for selective $\mathrm{CO}_{2}$ versus $\mathrm{N}_{2}$ adsorption, J. Mater. Chem. A, 2014, 2, 8719-8729.

48 N. López-Salas, M. C. Gutiérrez, C. O. Ania, M. A. Muñoz-Marquéz, M. L. Ferrer and F. del Monte, Nitrogen-doped carbons prepared from eutectic mixtures as metal-free oxygen reduction catalysts, J. Mater. Chem. A, 2016, 4, 478-488.

49 D. Carriazo, M. C. Gutierrez, F. Picó, J. M. Rojo, J. L. G. Fierro, M. L. Ferrer and F. del Monte, Phosphate-Functionalized Carbon Monoliths from Deep Eutectic Solvents and their Use as Monolithic Electrodes in Supercapacitors, ChemSusChem, 2012, 5, 1405-1409.

50 E. Posada, N. López-Salas, D. Carriazo, M. A. Muñoz-Marquéz, C. O. Ania, R. J. Riobóo, M. C. Gutierrez, M. L. Ferrer and F. del Monte, Predicting the suitability of aqueous solutions of deep eutectic solvents for preparation of co-continuous porous carbons via spinodal decomposition processes, Carbon, 2017, 123, 536-547.

51 N. López-Salas, M. C. Gutiérrez, C. O. Ania, J. L. G. Fierro, M. L. Ferrer and F. del Monte, Efficient nitrogen-doping and structural control of hierarchical carbons using unconventional precursors in the form of deep eutectic solvents, J. Mater. Chem. A, 2014, 2, 17387-17399.

52 X. Guo, W. Li, K. Nakanishi, K. Kanamori, Y. Zhu and H. Yang, Preparation of mullite monoliths with well-defined macropores and mesostructured skeletons via the sol-gel process accompanied by phase separation, J. Eur. Ceram. Soc., 2013, 33, 1967-1974.

53 X. Guo, K. Nakanishi, K. Kanamori, Y. Zhu and H. Yang, Preparation of macroporous cordierite monoliths via the sol-gel process accompanied by phase separation, J. Eur. Ceram. Soc., 2014, 34, 817-823.

54 C. Liang and S. Dai, Dual phase separation for synthesis of bimodal meso-/macroporous carbon monoliths, Chem. Mater., 2009, 21, 2115-2124.
55 K. Nakanishi and N. Tanaka, Sol-gel with phase separation. Hierarchically porous materials optimized for high-performance liquid chromatography separations, Acc. Chem. Res., 2007, 40, 863-873.

56 S. Peng, P. G. Hartley, T. C. Hughes and Q. Guo, Controlling morphology and porosity of porous siloxane membranes through water content of precursor microemulsion, Soft Matter, 2012, 8, 10493-10501.

57 S. Yu, F. L. Ng, K. C. C. Ma, A. A. Mon, F. L. Ng and Y. Y. Ng, Effect of porogenic solvent on the porous properties of polymer monoliths, J. Appl. Polym. Sci., 2013, 127, 2641-2647.

58 S. Yu, K. C. C. Ma, A. A. Mon, F. L. Ng and Y. Y. Ng, Controlling porous properties of polymer monoliths synthesized by photoinitiated polymerization, Polym. Int., 2013, 62, 406-410.

59 K. P. Constant, J.-R. Lee and Y.-M. Chiang, Microstructure development in furfuryl resin-derived microporous glassy carbons, J. Mater. Res., 2011, 11, 2338.

60 C. Ma, A. Laaksonen, C. Liu, X. Lu and X. Ji, The peculiar effect of water on ionic liquids and deep eutectic solvents, Chem. Soc. Rev., 2018, 47, 8685-8720.

61 M. Mijakovic, B. Kezic, L. Zoranic, F. Sokolic, A. Asenbaum, C. Pruner, E. Wilhelm and A. Perera, Ethanol-water mixtures: ultrasonics, Brillouin scattering and molecular dynamics, J. Mol. Liq., 2011, 164, 66-73.

62 A. Asenbaum, C. Pruner, E. Wilhelm, M. Mijakovic, L. Zorani!c, F. Sokolic, B. Kezic and A. Perera, Structural changes in ethanolewater mixtures: ultrasonics, Brillouin scattering and molecular dynamics studies, Vib. Spectrosc., 2012, 60, 102-106.

63 L. Lupi, L. Comez, C. Masciovecchio, A. Morresi, M. Paolantoni, P. Sassi, F. Scarponi and D. Fioretto, Hydrophobic hydration of tertbutyl alcohol studied by Brillouin light and inelastic ultraviolet scattering, J. Chem. Phys., 2011, 134, 055104.

64 M. Pochylski, F. Aliotta, Z. Blaszczak and J. Gapinski, Structuring effects and hydration phenomena in poly(ethylene glycol)/water mixtures investigated by Brillouin scattering, J. Phys. Chem. B, 2006, 110, 20533-20539.

65 L. Comez, L. Lupi, M. Paolantoni, F. Picchio and D. Fioretto, Hydration properties of small hydrophobic molecules by Brillouin light scattering, J. Chem. Phys., 2012, 137, 114509.

66 F. D’Amico, F. Bencivenga, G. Camisasca, A. Gessini, E. Principi, R. Cucini and C. Masciovecchio, Thermodynamic hydration shell behavior of Glycine, J. Chem. Phys., 2013, 139, 015101.

67 F. Aliotta, R. Ponterio, G. Salvato and M. Musso, Brillouin scattering evidence of nonideal mixing in methanol/CCl4 mixtures, J. Phys. Chem. B, 2004, 108, 732-736.

68 M. Pochylski, F. Aliotta, Z. Błaszczak and J. Gapinski, Structural relaxation processes in polyethylene glycol/CCl4 solutions by Brillouin scattering, J. Phys. Chem. B, 2005, 109, 4181-4188.

69 M. Pochylski, F. Aliotta, Z. Błaszczak and J. Gapinski, Evidences of nonideal mixing in poly(ethylene glycol)/organic solvent mixtures by Brillouin scattering, J. Phys. Chem. B, 2006, 110, 485-493.

70 R. Carplo, M. Mehlclc, F. Borsay, C. Petrovic and E. Yeager, Investigation of Aqueous Calcium Nitrate, Zinc Nitrate, and Zinc Chloride Solutions Using Acoustic Velocity Measurements, J. Phys. Chem., 1982, 86, 4980-4987.

71 E. Posada, N. López-Salas, R. J. Riobóo, M. L. Ferrer, M. C. Gutierrez and F. del Monte, Reline aqueous solutions behaving as liquid mixtures of $\mathrm{H}$-bonded co-solvents: microphase segregation and formation of co-continuous structures as indicated by Brillouin and ${ }^{1}$ H NMR spectroscopies, Phys. Chem. Chem. Phys., 2017, 19, 17103-17110.

72 E. Posada, M. J. Roldán-Ruiz, R. J. Riobóo, M. C. Gutierrez, M. L. Ferrer and F. del Monte, Nanophase separation in aqueous dilutions of a ternary DES as revealed by Brillouin and NMR spectroscopy, J. Mol. Liq., 2019, 276, 196-203.

73 M. C. Gutierrez, C. R. Mateo, M. L. Ferrer and F. del Monte, Freezedrying of aqueous solutions of deep eutectic solvents: A suitable approach to deep eutectic suspensions of self-assembled structures, Langmuir, 2009, 25, 5509-5515.

74 O. S. Hammond, D. T. Bowron and K. J. Edler, Water upon Deep Eutectic Solvent Nanostructure: An Unusual Transition from Ionic Mixture to Aqueous Solution, Angew. Chem., Int. Ed., 2017, 56, 9782-9785.

75 H. Passos, D. J. P. Tavares, A. M. Ferreira, M. G. Freire and J. A. P. Coutinho, Are aqueous biphasic systems composed of deep eutectic solvents ternary or quaternary systems?, ACS Sustainable Chem. Eng., 2016, 4, 2881-2886.

76 O. S. Hammond, D. T. Bowron, A. J. Jackson, T. Arnold, A. SanchezFernandez, N. Tsapatsaris, V. Garcia Sakai and K. J. Edler, Resilience of 
malic acid natural deep eutectic solvent nanostructure to solidification and hydration, J. Phys. Chem. B, 2017, 121, 7473-7483.

77 M. J. Roldán-Ruiz, R. J. Jiménez-Riobóo, M. C. Gutierrez, M. L. Ferrer and F. del Monte, Brillouin and NMR spectroscopic studies of aqueous dilutions of malicine: determining the dilution range for transition from a "water-in-DES" system to a "DES-in-water" one, J. Mol. Liq., 2019, 284, 175-181.

78 N. López-Salas, J. M. Vicent-Luna, S. Imberti, E. Posada, M. J. Roldán-Ruiz, J. A. Anta, S. R. E. G. Balestra, R. M. Madero Castro, S. Calero, R. J. Jiménez-Riobóo, M. C. Gutierrez, M. L. Ferrer and F. del Monte, Looking at the "Water-in-Deep-Eutectic-Solvent" System: A Dilution Range for High Performance Eutectics, ACS Sustainable Chem. Eng., 2019, 7, 17565-17573.

79 A. Jani, T. Sohier and D. Morineau, Phase behavior of aqueous solutions of ethaline deep eutectic solvents, J. Mol. Liq., 2020, 304, 112701.

80 S. García-Argüelles, C. García, M. C. Serrano, M. C. Gutierrez, M. L. Ferrer and F. del Monte, Near-to-eutectic mixtures as bifunctional catalysts in the low-temperature ring opening polymerization of E-caprolactone, Green Chem., 2015, 17, 3632-3643.

81 M. G. Pérez-García, M. C. Gutierrez, J. D. Mota-Morales, G. Luna-Bárcenas and F. del Monte, Synthesis of Biodegradable Macroporous Poly(Llactide)/Poly(e-caprolactone) Blend Using Oil-in-Eutectic-Mixture High-Internal-Phase Emulsions as Template, ACS Appl. Mater. Interfaces, 2016, 8, 16939-16949.

82 R. J. Sanchéz-Leija, N. López-Salas, J. L. G. Fierro, M. C. Gutierrez, M. L. Ferrer, J. D. Mota-Morales, G. Luna-Bárcenas and F. del Monte,
Deep eutectic solvents as active media for the preparation of highly conducting 3D free-standing PANI xerogels and their derived N-doped and N,P-codoped porous carbons, Carbon, 2019, 146, 813-826.

83 T.-J. Park and S. H. Lee, Deep eutectic solvent systems for $\mathrm{FeCl}_{3}$ catalyzed oxidative polymerization of 3-octylthiophene, Green Chem., 2017, 19, 910-913.

84 (a) L. Quirós-Montes, G. A. Carriedo, J. García-Álvarez and A. Presa Soto, Deep eutectic solvents for Cu-catalysed ARGET ATRP under an air atmosphere: a sustainable and efficient route to poly(methyl methacrylate) using a recyclable $\mathrm{Cu}(\mathrm{II})$ metal-organic framework, Green Chem., 2019, 21, 5865-5875; (b) A. Sanchéz-Condado, G. A. Carriedo, A. Presa Soto, M. J. Rodríguez-Álvarez, J. García-Álvarez and E. Hevia, Organolithium-Initiated Polymerization of Olefins in Deep Eutectic Solvents under Aerobic Conditions, ChemSusChem, 2019, 12, 3134-3143; (c) J. Wang, J. Han, M. Y. Khan, D. He, H. Peng, D. Chen, X. Xie and Z. Xue, Deep eutectic solvents for green and efficient iron-mediated ligand-free atom transfer radical polymerization, Polym. Chem., 2017, 8, 1616-1627.

85 (a) Z. Lin, A. M. Z. Slawin and R. E. Morris, Chiral induction in the ionothermal synthesis of a 3-D coordination polymer, J. Am. Chem. Soc., 2007, 129, 4880-4881; (b) Z. Lin, D. S. Wragg, P. Lightfoot and R. E. Morris, A novel non-centrosymmetric metallophosphate-borate compound via ionothermal synthesis, Dalton Trans., 2009, 5287-5289.

86 T. Palomba, G. Ciancaleoni, T. Del Giacco, R. Germani, F. Ianni and M. Tiecco, Deep Eutectic Solvents formed by chiral components as chiral reaction media and studies of their structural properties, J. Mol. Liq., 2018, 262, 285-294. 